\title{
A Retrospective Study of Acute Poisoning Cases and Their Management at Emergency Department of Dessie Referral Hospital, Northeast Ethiopia
}

This article was published in the following Dove Press journal:

Drug, Healthcare and Patient Safety

\author{
Abebe Getie \\ Yaschilal Muche Belayneh \\ Department of Pharmacy, College of \\ Medicine and Health Sciences, Wollo \\ University, Dessie, Ethiopia
}

Background: Poisoning causes significant patient morbidity and mortality worldwide. It is a common reason for emergency department visits and hospitalizations. Acute poisoning needs immediate effective management to prevent patient mortality or sequela. This study was carried out to determine the pattern of acute poisoning cases and their management at the emergency department of Dessie referral hospital, northeast Ethiopia.

Methods: A retrospective cross-sectional study of all registered poisoning cases managed at the emergency department of Dessie referral hospital was conducted from March 10 to May 2, 2018.

Results: There were a total of 147 registered poisoning cases listed in the registry during the study period, of which 120 cases $(81.6 \%)$ had complete data and were included in the study. Among the total of 120 studied poisoning cases, 66 (55\%) were females, and $53(44.2 \%)$ were in the age group of 21-30 years. The causative poison was documented for 118 cases. Organophosphates were the most common poisoning agents involved in $54(45 \%)$ of the cases followed by sodium hypochlorite, 27 (22.5\%), and food poisoning, 19 (15.8\%). Among the total patients, $77(64.2 \%)$ were self-poisoned intentionally, $31(25.8 \%)$ were poisoned in an unintentional manner and the rest, $12(10 \%)$, had an unknown manner of poisoning. Mental disorder, 25 (20.8\%); family disharmony, 23 (19.2\%); and marital disharmony, 19 $(15.8 \%)$ were the three most common causes of intentional poisoning. In all cases of acute poisoning, both pharmacological and non-pharmacological treatment approaches were used. Cimetidine was the most commonly used pharmacologic treatment, 118 (98.3\%), followed by antiemetic, 107 (89.2\%); proton pump inhibitor, 87 (72.5\%), and atropine, 67 (55.8\%). ANOVA did not show a statistically significant difference $(P>0.05)$ in the frequency of poisoning cases across seasons.

Conclusion: Among 120 acute poisoning cases, 77 (64.2\%) were intentional poisoning cases. Organophosphate poisoning accounts for $45 \%$ of the total poisoning cases. The three major reasons for intentional poisoning were mental disorders $(20.8 \%)$, family disharmony (19.2\%) and marital disharmony (15.8\%). Cimetidine (98.3\%) was the most commonly used pharmacologic treatment of the poisoning cases.

Keywords: acute poisoning, emergency department, organophosphate poisoning

\section{Background}

The herald of modern toxicology, Paracelsus, supposed that everything is poison and only the dose plays a pivotal role. ${ }^{1}$ Poison may be defined as any agent that can injure, kill, or impair normal physiological function in humans, producing general or local damage or dysfunction in the body. ${ }^{2}$ Poisoning is a global medico-social problem.

\section{Belayneh}

Department of Pharmacy, College of

Medicine and Health Sciences, Wollo

University, P.O. Box II45, Dessie,

Ethiopia

Tel +251918092466

Email yaschilal.muche19@gmail.com 
Acute poisoning is a common reason for visits to emergency departments and hospitalizations worldwide, and it is a common cause of morbidity and mortality worldwide. Understanding the epidemiology of poisoning and its changes is important to both emergency physicians and public health practitioners. ${ }^{2-4}$ Poisoning may occur either intentionally or unintentionally. Intentional poisoning is the result of a person taking or giving a substance with the intention of causing harm, while unintentional poisoning occurs if a person taking or giving a substance did not mean to cause harm. The incidence of poisoning cases is increasing due to changes in the lifestyle and social behavior of humans. ${ }^{5}$ According to a report from WHO, there were 346,000 deaths (3.5 per 100,000) worldwide from unintentional poisoning in 2004. Of these deaths, 91\% occurred in low- and middleincome countries. In the same year, intentional poisoning caused the loss of over 7.4 million years of healthy life. The prevalence and types of poisoning vary considerably across the world and depend on socioeconomic status and cultural practices, as well as on local industrial and agricultural activities. Household chemical agents and prescribed drugs are the most common poisoning agents in the developed world, but agrochemicals are the most common poisoning agents in developing countries. ${ }^{6}$ Poisoning is very common in developing countries, and because of the weak regulations and poor health-care services, the consequences of poisoning are much worse than in the developed world. Pesticides are the most common chemicals used to inflict self-harm in developing countries. ${ }^{7}$

Management of acute poisoning consists of prevention of cross-contamination, identification of toxins through history or physical examination, supportive and symptomatic care, decontamination, elimination, and antidote therapy. ${ }^{8}$

The nature of poisons used varies in different parts of the world and may vary even in different parts of the same country depending on the socioeconomic factors and cultural diversity. It is important to know the nature and severity of poisoning in order to take prompt appropriate measures to save lives and reduce morbidity and mortality. ${ }^{9}$ As a result, this study was conducted to determine the pattern of acute poisoning cases and their management at the emergency department of Dessie referral hospital, northeast Ethiopia.

\section{Methods and Materials}

\section{Study Area and Period}

The study was conducted at the emergency department of Dessie referral hospital from March 10 to May 2, 2018.
The hospital is located in Dessie town (latitude: $11.15 \mathrm{~N}$; longitude: $39.64 \mathrm{E}$; altitude: $2518.00 \mathrm{~m}$ (8261.15 ft)), south Wollo zone of northeast Ethiopia which is $401 \mathrm{~km}$ from Addis Ababa. The hospital provides specialized health services to the surrounding population. It has different departments such as Emergency, Ophthalmology, Surgery, Obstetrics and Gynecology, Maternal and Child Health, Medical, Pediatrics and Neonatal care, Laboratory, Psychiatry, Pharmacy, Antiretroviral, and Tuberculosis clinics.

\section{Study Design}

A retrospective cross-sectional study design was used.

\section{Source of Population}

All patients who had visited the emergency department of DRH are the source population for this study.

\section{Study Population}

All patients who had visited the emergency department of DRH due to acute poisoning.

\section{Inclusion and Exclusion Criteria Inclusion Criteria}

- All acutely poisoned patients who had visited the emergency department and were listed in the registry emergency cases during the study period.

\section{Exclusion Criteria}

- Acute poisoning cases with incomplete information on the patient card

\section{Sampling Technique and Sample Size}

There were a total of 147 registered poisoning cases listed in the registry of the emergency department during the study period, of which 120 cases had complete data, and were included in the study.

\section{Study Variables} Independent Variable

- Age, sex, residence, route of poisoning, type of poisoning and season of poisoning.

\section{Dependent Variables}

- Acute poisoning. 


\section{Data Collection Material}

A data collection checklist containing the variables to be measured was developed and used to collect the necessary data.

\section{Data Collection Method}

The data were collected from the patient card using the pretested data collection checklist after preparing the study materials and obtaining permission (ethical clearance) by selecting the card number of poisoning cases from the registration manual of the emergency department.

\section{Data Quality Assurance}

Data were checked for completeness, accuracy, and consistency immediately after collection and appropriately arranged and kept in a secured place for compilation and analysis.

\section{Data Processing and Analysis}

SPSS Version 20 Software was used for statistical analysis. Descriptive statistical tools were used to report percentage and frequency distribution tables. One-way analysis of variance (ANOVA) followed by Tuckey's post hoc multiple comparison test was used to compare the frequency of poisoning cases across seasons. $P$-values $<0.05$ were considered statistically significant.

\section{Ethical Consideration}

The study was approved by the ethical review committee of the college of medicine and health sciences, Wollo University. Permission to conduct the study was granted from Dessie referral hospital after a formal request with an official letter from Wollo University. Confidentiality of patient-specific data was maintained throughout the study.

\section{Definition of Terms}

Poisoning: this refers to the development of harmful effects following exposure to chemicals, drugs, or other xenobiotics. ${ }^{10}$

Intentional poisoning: this is the result of a person taking or giving a substance with the intention of causing harm. ${ }^{5}$
Unintentional poisoning: this is poisoning that occurs if a person taking or giving a substance did not mean to cause harm. ${ }^{5}$

Organophosphate poisoning: this is poisoning due to organophosphate compounds which are the organic derivatives of phosphorous containing acids that have an effect on neuromuscular junction and autonomic ganglia. ${ }^{11}$

\section{Result}

\section{Patient Demographic Characteristics}

Of the total 120 poisoned patients included in this study, $54(45 \%)$ were male and $66(55 \%)$ were females with a large portion of poisoned patients $(44.17 \%)$ in the age group of 21-30 yrs. Out of the total poisoning cases, 42 (35\%) were from a rural area and 78 (65\%) were from an urban area (Table 1).

\section{Status of the Patient When Coming to the Hospital}

The status of the patient when coming to the hospital was analyzed, and out of 120 poisoned patients $82(68.3 \%)$ had conscious status; the rest, 38 (31.7\%), were unconscious (Figure 1).

\section{Type of Poisoning Agents}

Out of 120 poisoned patients, 118 were exposed to a known poisoning agent and the rest 2 were poisoned with an unknown agent. Out of these 118 known poisoned cases, the most common poisoning agents were organophosphate (45\%), sodium hypochlorite $(22.5 \%)$, food poisoning (15.8\%), carbon monoxide (5\%), prescription drugs $(4.2 \%)$, kerosene (3.3\%), and herbal medication (2.5\%) (Table 2).

\section{Dosage Form of Poisoning Agents}

Poisoning chemicals have different dosage forms such as liquid, solid, and gaseous. The most common dosage form of causative poisoning agents in this study was liquid $(49.2 \%)$ followed by solid (39.1\%), and gaseous (7.5\%) (Figure 2).

The most common route of poisoning was oral, 111 $(92.5 \%)$, followed by inhalational route, 9 (7.5\%).

Table I Patient Demographic Characteristics

\begin{tabular}{|l|l|l|l|l|l|l|l|l|l|}
\hline & \multicolumn{2}{|l|}{ Gender } & \multicolumn{2}{l|}{ Age in Years } & \multicolumn{2}{l|}{ Residence } \\
\cline { 2 - 11 } & Male & Female & $\mathbf{I I - 2 0}$ & $\mathbf{2 1 - 3 0}$ & $\mathbf{3 1 - 4 0}$ & $\mathbf{4 I - 5 0}$ & $\mathbf{7 6 0}$ & Urban & Rural \\
\hline Frequency & 54 & 66 & 39 & 53 & 21 & 5 & 2 & 78 & 42 \\
Percentage (\%) & $45 \%$ & $55 \%$ & $32.5 \%$ & $44.2 \%$ & $17.5 \%$ & $4.2 \%$ & $1.7 \%$ & $65 \%$ & $35 \%$ \\
\hline
\end{tabular}




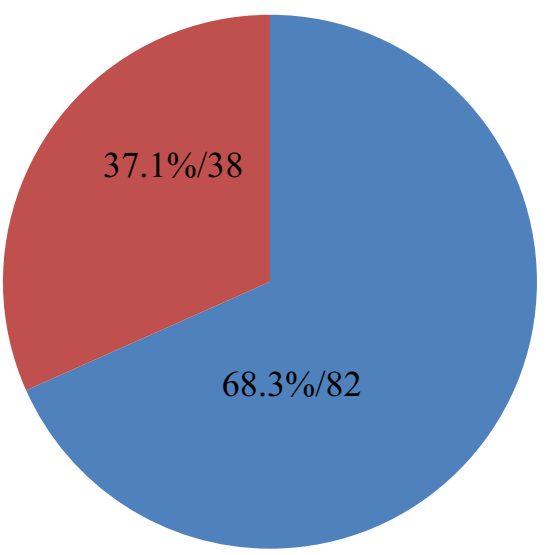

Figure I Patient status when coming to the hospital.

\section{Manner of Poisoning}

Among the total 120 poisoned patients, 77 (64.2\%) were intentionally poisoned, $31(25.8 \%)$ were unintentionally poisoned and manner of poisoning was unknown in the remaining $12(10 \%)$ of the cases (Table 3 ).

\section{Reasoning of Patients for Taking the Poison}

In this study, $81(87.5 \%)$ of the total studied patients had a known reason for taking poison while the rest, 39 (32.5\%), had an unknown reason. Among the 81 cases with a known reason for poisoning, family disharmony (19.2\%) was the most common reason for poisoning followed by mental disorder (20.8\%), marital disharmony $(15.8 \%)$, and traditional medicine $(2.5 \%)$ (Table 4$)$.

\section{Time of Poisoning}

Among the total of 120 poisoning cases, 63 (52.5\%) happened during the daytime, 47 (39.2\%) happened during

Table 2 Type of Poisoning Agent at the Emergency Department of Dessie Referral Hospital, Northeast Ethiopia

\begin{tabular}{|l|l|l|}
\hline Type of Poisoning Agent & Frequency & Percentage (\%) \\
\hline Organophosphate & 54 & $45 \%$ \\
Sodium hypochlorite & 27 & $22.5 \%$ \\
Food poisoning & 19 & $15.8 \%$ \\
Carbon monoxide & 6 & $5 \%$ \\
Prescription drugs & 5 & $4.2 \%$ \\
Kerosene & 4 & $3.3 \%$ \\
Herbal medication & 3 & $2.5 \%$ \\
Unknown & 2 & $1.7 \%$ \\
Total & 120 & $100 \%$ \\
\hline
\end{tabular}

\section{Poison dosage form}

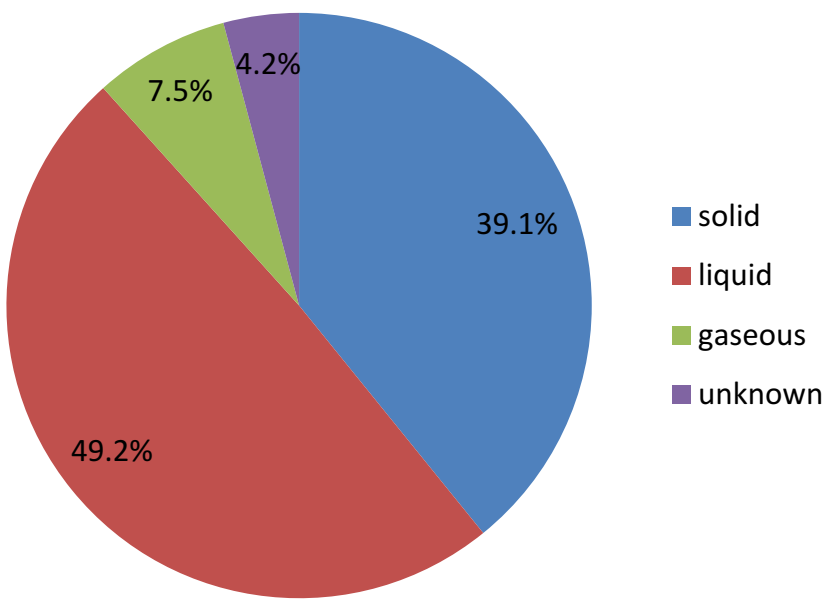

Figure 2 Dosage form of poisoning agents.

the night, but the time of poisoning was unknown for 10 $(8.3 \%)$ poisoning cases (Table 5).

\section{Time of Arrival at the Hospital}

It is known that time of arrival has great impact on the mode of management and most of the poisoned patients (50.8\%) arrived between 2 and $4 \mathrm{~h}$ after poisoning $(\mathrm{IQR}=2)$, followed by within $2 \mathrm{~h}$ of poisoning $(27.5 \%)$ and after $4 \mathrm{~h}(21.7 \%)$ (Table 6).

\section{Source of Poisoning Agents}

The home was the most common source of poisoning agents, 73 (60.8\%), followed by a hotel, 18 (15\%), and unknown sources, 29 (24.2\%) (Table 7).

Table 3 Manner of Poisoning at Emergency Department of Dessie Referral Hospital, Northeast Ethiopia

\begin{tabular}{|l|l|l|l|}
\hline $\begin{array}{l}\text { Manner of } \\
\text { Poisoning }\end{array}$ & Gender & Frequency & $\begin{array}{l}\text { Percentage } \\
\text { (\%) }\end{array}$ \\
\hline Intentional & Female & 44 & $36.7 \%$ \\
& Male & 33 & $27.5 \%$ \\
& Total & 77 & $64.2 \%$ \\
\hline Unintentional & Female & 17 & $14.2 \%$ \\
& Male & 14 & $11.7 \%$ \\
& Total & 31 & $25.8 \%$ \\
\hline Unknown & Male & 7 & $5.8 \%$ \\
& Female & 5 & $4.2 \%$ \\
& Total & 12 & $10 \%$ \\
\hline
\end{tabular}


Table 4 Reasoning of Patients for Taking the Poison

\begin{tabular}{|l|l|l|}
\hline Reason for Poisoning & Frequency & Percentage (\%) \\
\hline Mental disorder & 25 & $20.8 \%$ \\
Family disharmony & 23 & $19.2 \%$ \\
Marital disharmony & 19 & $15.8 \%$ \\
Traditional medicine & 3 & $2.5 \%$ \\
Other & 11 & $9.2 \%$ \\
Unknown & 39 & $32.5 \%$ \\
Total & 120 & $100 \%$ \\
\hline
\end{tabular}

Table 5 Time of Poisoning

\begin{tabular}{|l|l|l|}
\hline Time & Number & Percentage (\%) \\
\hline Day & 63 & $52.5 \%$ \\
Night & 47 & $39.2 \%$ \\
Unknown & 10 & $8.3 \%$ \\
Total & 120 & $100 \%$ \\
\hline
\end{tabular}

Table 6 Time of Arrival to the Emergency Department of the Hospital

\begin{tabular}{|l|l|l|}
\hline $\begin{array}{l}\text { Duration of Time Up to Arrival } \\
\text { (hr) }\end{array}$ & Frequency & $\begin{array}{l}\text { Percentage } \\
\text { (\%) }\end{array}$ \\
\hline$<2$ & 33 & $27.5 \%$ \\
$2-4$ & 61 & $50.8 \%$ \\
$>4$ & 26 & $21.7 \%$ \\
Total & 120 & $100 \%$ \\
\hline
\end{tabular}

Table 7 Source of Poisoning Agents

\begin{tabular}{|l|l|l|}
\hline Source & Frequency & Percentage (\%) \\
\hline Home & 73 & $60.8 \%$ \\
Hotel & 18 & $15 \%$ \\
Unknown & 29 & $24.2 \%$ \\
Total & 120 & $100 \%$ \\
\hline
\end{tabular}

\section{Season of Poisoning}

Season of poisoning was classified as spring, summer, autumn, and winter. Poisoning cases were more common during the autumn (31.7\%) and less common during the spring season (15.8\%), but ANOVA did not show a statistically significant difference $(P>0.05)$ in the frequency of poisoning cases across seasons (Table 8).

\section{Treatment of Poisoning Cases}

In this study, both pharmacological and non-pharmacological approaches were used as a treatment for poisoning cases. The most commonly used pharmacological treatments were
Table 8 Seasonal Distribution of Poisoning Cases

\begin{tabular}{|l|l|l|l|}
\hline Season & Month & Frequency & Percentage (\%) \\
\hline Spring & September & 4 & $3.3 \%$ \\
& October & 7 & $5.8 \%$ \\
& November & 8 & $6.7 \%$ \\
& Total & 19 & $15.8 \%$ \\
\hline \multirow{2}{*}{ Summer } & December & 4 & $3.3 \%$ \\
& January & 13 & $10.8 \%$ \\
& February & 11 & $9.2 \%$ \\
& Total & 28 & $23.3 \%$ \\
\hline \multirow{2}{*}{ Autumn } & March & 14 & $11.7 \%$ \\
& April & 6 & $5 \%$ \\
& May & 18 & $15 \%$ \\
& Total & 38 & $31.7 \%$ \\
\hline \multirow{2}{*}{ Winter } & June & 25 & $20.8 \%$ \\
& July & 6 & $5 \%$ \\
& August & 4 & $3.3 \%$ \\
& Total & 35 & $29.1 \%$ \\
\hline
\end{tabular}

cimetidine, $98.3 \%$, followed by metoclopramide, $89.2 \%$; PPIs (omeprazole and pantoprazole), 72.5\%; atropine, 55.8\%; diazepam, 20.8\%; antibiotics, $17.5 \%$; and antacids, $15.8 \%$. Additionally, non-pharmacologic treatments were used including IV fluid (96.6\%), gastric lavage (48.3\%), NG tube feeding (52.5\%), milk (12.5\%), and water $(0.58 \%)$ (Table 9).

\section{Duration of Hospital Stay}

The duration of hospital stay depends on the response rate and presence of complications. In this study, $89.2 \%$ of the poisoned patients were hospitalized for 1 to 2 days at the emergency department and the rest, $10.8 \%$, were hospitalized for more than 2 days (IQR=1) (Table 10).

\section{Treatment Outcome}

Of the total of 120 poisoned patients, $112(93.3 \%)$ were cured after treatment, and the remaining $8(6.6 \%)$ died due to organophosphate ${ }^{5}$ and carbon monoxide (1 individual) poisoning (Table 11).

\section{Discussion}

In this study, poisoning was more frequently observed in the age group of $21-30$ years $(44.7 \%)$ and females (55\%). This finding was similar to a retrospective study in India, which reported frequent poisoning in the age group of 21-30 yrs (45\%) and females (58.7\%). ${ }^{3}$ Additionally, the present study has a similar finding to a prospective study 
Table 9 Treatment of Acute Poisoning at the Emergency Department of Dessie Referral Hospital, Northeast Ethiopia

\begin{tabular}{|l|l|l|l|}
\hline \multicolumn{2}{|l|}{ Treatment } & Frequency & $\begin{array}{l}\text { Percentage } \\
\text { (\%) }\end{array}$ \\
\hline $\begin{array}{l}\text { Non- } \\
\text { pharmacologic }\end{array}$ & Iv fluid & 116 & $96.6 \%$ \\
& NG tube & 63 & $52.5 \%$ \\
& feeding & & \\
& Gastric lavage & 58 & $48.3 \%$ \\
& Milk & 15 & $12.5 \%$ \\
& Water & 7 & $0.58 \%$ \\
\hline Pharmacologic & Cimetidine & 118 & $98.3 \%$ \\
& Metoclopramide & 107 & $89.2 \%$ \\
& PPls & 87 & $72.5 \%$ \\
& Atropine & 67 & $55.8 \%$ \\
& Diazepam & 25 & $20.8 \%$ \\
& Antibiotics & 21 & $17.5 \%$ \\
& Antacid & 19 & $15.8 \%$ \\
\hline
\end{tabular}

Table 10 Duration of Hospital Stay of Poisoned Patients

\begin{tabular}{|l|l|l|}
\hline Duration of Stay (Day) & Frequency & Percentage (\%) \\
\hline I-2 & 107 & 89.2 \\
$>2$ & 13 & 10.8 \\
\hline
\end{tabular}

Table I I Distribution of Treatment Outcome

\begin{tabular}{|l|l|l|}
\hline Outcome & Frequency & Percentage (\%) \\
\hline Cure & 112 & 93.3 \\
Death & 8 & 6.6 \\
\hline
\end{tabular}

of acute poisoning in Greece which reported 54.6-67.4\% of poisoning cases in females. ${ }^{12}$

Organophosphate compounds were the most common causes of poisoning $(45 \%)$ in this study. Similarly, organophosphates were the most common poisoning agents (57.6\%) in a study at a large teaching hospital in north India. ${ }^{9}$ Another study in India reported a similar result with organophosphates being the most common causative agents. ${ }^{3}$

In this study, acute poisoning has a higher distribution in urban residents (65\%) than rural residents. Similar studies from Greece $^{12}$ and Gondar, Ethiopia ${ }^{8}$ reported a high frequency of poisoning in urban residents, but a study in India shows a high frequency of poisoning in rural residents $(69.23 \%){ }^{9}$

Intentional poisoning was the most common (64.2\%) manner of poisoning in this study. Similarly, other studies conducted in Nepal, India, and Addis Ababa, Ethiopia showed intentional poisoning is more common, accounting for $77.8 \%$, $79.2 \%$, and $96.6 \%$ of poisoning cases, respectively. ${ }^{3,5,13}$
This study showed that a liquid dosage form was the most common physical form of poisoning agents and the oral route was the most common route of poisoning. Similarly, other studies conducted in south India, south Turkey, and Gondar, Ethiopia showed the oral route was the most common route of poisoning. ${ }^{2,8,14}$

Mental disorder followed by family disharmony were the two most common reasons for taking poison in this study, but another study conducted at Tikur Anbessa specialized teaching hospital in Addis Ababa, Ethiopia reported temporary quarrel as the most common reason, followed by emotional disturbance. ${ }^{5}$ This difference is possibly due to the high prevalence of substance abuse and related mental illness in Dessie town.

In this study the main source of poisoning agents was the home $(60.8 \%)$ followed by a hotel $(15 \%)$. This is comparable to the finding of a study in Gondar, Ethiopia in which hotels and the home were the main sources of poisoning agents. ${ }^{8}$ A study at a tertiary care teaching hospital in South India showed that poisoning cases were more frequent during the summer season $(28.1 \%)$ followed by winter $(26 \%){ }^{2}$ but in the current study a higher frequency of poisoning cases was observed during the autumn (37.1\%) followed by winter $(29.1 \%)$.

Gastric decontamination using gastric lavage and administration of activated charcoal is known to limit the absorption of ingested poisons, provided that they are given within one-hour post-ingestion and only if the airway is protected. In this study, gastric decontamination by lavage was done in $48.3 \%$ of the cases. In another study from India gastric lavage was conducted for $80 \%$ of the poisoning cases. ${ }^{3}$ Additionally, studies in other parts of Ethiopia which were conducted in Jimma and north Gondar reported that gastric decontamination was conducted in $81 \%$ and $74 \%$ of the cases, respectively. ${ }^{6,8}$ Lower utilization of gastric lavage in the current study may result from delayed arrival of poisoned patients in the emergency department.

The use of antidotes is specific for the poisoning case. In this study, $55.8 \%$ of poisoned cases were treated with atropine. Similarly, in India, $45.5 \%{ }^{3}$ and in Jimma, Ethiopia, $44.4 \%$ of the cases were treated with atropine. ${ }^{6}$ This difference in the use of atropine is due to the higher frequency of organophosphate poisoning in the current study. In this study, an antiemetic (metoclopramide) was used in $89.2 \%$ of the poisoning cases. Similarly, the study in India reported $87.1 \%$ of the cases were treated with an antiemetic. ${ }^{3}$ Iv fluids were administered for most of the cases $(96.6 \%)$ in the current study, but in India, $40 \%$ of the poisoning cases were treated 
with iv fluids. ${ }^{3}$ In this study, most of the acute poisoning cases $(93.3 \%)$ were cured, but in another study which was conducted in Jimma, Ethiopia $63.3 \%$ of the poisoning cases were cured after treatment. ${ }^{6}$

This study has limitations since it did not show the overall prevalence of poisoning cases at the emergency department due to poor registration of emergency cases. Additionally, the sample size is small which may affect the representativeness of the results.

\section{Conclusion}

Among 120 acute poisoning cases included in the study, $77 \quad(64.2 \%)$ were intentional poisoning cases. Organophosphate poisoning accounts for $45 \%$ of the total poisoning cases. The three major reasons for intentional poisoning were mental disorders (20.8\%), family disharmony (19.2\%) and marital disharmony (15.8\%). Cimetidine was the most commonly used pharmacologic treatment, 118 (98.3\%), followed by antiemetic, 107 (89.2\%); proton pump inhibitor, 87 (72.5\%), and atropine, $67(55.8 \%)$. Improving the regulation of pesticides and other poisoning chemicals in the country can reduce the occurrence of poisoning cases.

\section{Abbreviations}

DRH, Dessie referral hospital; IV, intravenous; NG, nasogastric; PPI, proton pump inhibitor.

\section{Ethics Approval}

The study has been approved by the ethical review committee of the college of medicine and health sciences, Wollo University. According to Article 32 of the Declaration of Helsinki - Ethical Principles for Medical Research Involving Human Subjects, the research can be done only after consideration and approval of a research ethics committee in situations where consent would be impossible or impracticable to obtain. As a result, consent to review medical records of patients was not required by the ethical review committee. Patient-related data were kept confidential throughout the study.

\section{Data Sharing Statement}

All the datasets used/or analyzed during the current study are available from the corresponding author on reasonable request.

\section{Acknowledgments}

We are thankful to the staffs of the Dessie referral hospital for their assistance during the data collection.

\section{Author Contributions}

Both authors contributed to data analysis, drafting or revising the article, gave final approval of the version to be published, and agree to be accountable for all aspects of the work.

\section{Disclosure}

Both authors declare that there is no conflict of interest.

\section{References}

1. Pokhrel D, Pant S, Pradhan A, Mansoor S. A comparative retrospective study of poisoning cases in central, zonal and district hospitals. Kathmandu Univ Med J Eng Technol. 2008;4(1):40-48.

2. Jesslin J, Adepu R, Churi S. Assessment of prevalence and mortality incidences due to poisoning in a South Indian tertiary care teaching hospital. Indian J Pharm Sci. 2010;72(5):587. doi:10.4103/0250474X.78525

3. Maheswari E, Abraham L, Chacko CS, Saraswathy GR, Ramesh AC. Assessment of pattern, severity and outcome of poisoning in emergency care unit. J Appl Pharm Sci. 2016;6(12):178-183. doi:10.7324/ JAPS

4. Rutto J, Mwaura J, Chepchirchir A, Odero T. Nurse's Knowledge, Attitude and Practice on the Initial Management of Acute Poisoning Among Adult Casualties. Kenya: Study at Kenyatta National Hospital; 2012.

5. Desalew M, Aklilu A, Amanuel A, Addisu M, Ethiopia T. Pattern of acute adult poisoning at Tikur Anbessa specialized teaching hospital, a retrospective study, Ethiopia. Hum Exp Toxicol. 2011;30 (7):523-527. doi:10.1177/0960327110377520

6. Teklemariam E, Tesema S, Jemal A. Pattern of acute poisoning in Jimma University Specialized Hospital, South West Ethiopia. World J Emerg Surg. 2016;7(4):290. doi:10.5847/wjem.j.1920-8642.2016.04.009

7. Kaale E, Mori A, Risha P, Hasham S, Mwambete K. A retrospective study of poisoning at Muhimbili National Hospital in Dar-Es Salaam, Tanzania. J Public Health Front. 2013;2(1):21-26. doi:10.5963/ PHF0201003

8. Adinew GM, Woredekal AT, DeVos EL, Birru EM, Abdulwahib MB Poisoning cases and their management in emergency centres of government hospitals in northwest Ethiopia. Afr J Emerg Med. 2017;7(2):74-78. doi:10.1016/j.afjem.2017.04.005

9. Hakim A, Khurshid R, Mufti S, Krishan K, Singh Y. Pattern, profile and outcome of poisoning cases: a study at a large teaching hospital in India. JK Pract. 2014;19(1-2):36-40.

10. Chhetri HP, Khan G, Acharya A, et al. Acute organophosphate poisoning: pattern, management and outcomes. Pharmacol Online. 2008;1:48-54.

11. Azazh A. Severe organophosphate poisoning with delayed cholinergic crisis, intermediate syndrome and organophosphate induced delayed polyneuropathy on succession. Ethiop J Health Sci. 2011;21(3).

12. Exiara T, Mavrakanas TA, Papazoglou L, Papazoglou D, Christakidis D, Maltezos E. A prospective study of acute poisonings in a sample of Greek patients. Cent Eur J Public Health. 2009;17 (3):158-160. doi:10.21101/cejph.a3522

13. Marahatta S, Singh J, Shrestha R, Koju R. Poisoning cases attending Emergency department in Dhulikhel hospital-Kathmandu university teaching hospital. Kathmandu Univ Med J. 2009;7(2):152-156. doi:10.3126/kumj.v7i2.2711

14. Zöhre E, Ayrik C, Bozkurt S, et al. Retrospective analysis of poisoning cases admitted to the emergency medicine. Arch Iran Med. 2015;18(2):117. doi:10.15184/AIM.006 


\section{Publish your work in this journal}

Drug, Healthcare and Patient Safety is an international, peer-reviewed open-access journal exploring patient safety issues in the healthcare continuum from diagnostic and screening interventions through to treatment, drug therapy and surgery. The journal is characterized by the rapid reporting of reviews, original research, clinical, epidemiological and post-marketing surveillance studies, risk management, health literacy and educational programs across all areas of healthcare delivery. The manuscript management system is completely online and includes a very quick and fair peer-review system. Visit http://www.dovepress.com/testimonials.php to read real quotes from published authors.

Submit your manuscript here: https://www.dovepress.com/drug-healthcare-and-patient-safety-journal 